\title{
Cavitation Analysis of Kaplan-Series Propeller: Effect of Pitch Ratio and nProp using CFD
}

\author{
Mohammad Danil Arifin ${ }^{1}$, Frengki Mohamad Felayati ${ }^{2}$ \\ (Received: 24 February 2021 / Revised: 01 March 2021 / Accepted: 03 March 2021)
}

\begin{abstract}
- _ cavitation is defined as a phenomenon or action of the traveling bubbles that pass through the hydrofoil in which the reduction of pressure below the liquid's vapor pressure leads to the formation of small vapor bubbles (or cavities) caused by the dynamic pressure of the propeller blades. It caused some effects on the propeller of the ship i.e. it can greatly reduce a ship's propelling efficiency, damaged propeller material or blade erosion, vibration, and disturbance noises. Cavitation can be minimized by proper attention regarding the design of the propellers and variation of propeller variables parameters. For that reason, this research conducts a cavitation analysis on the Kaplan-Series of the CPP by varying $P / D_{b}=0.4, P / D_{b}=0.6$, and $P / D_{b}=0.8$; also the rotational speed of the propeller (nProp) i.e. $125 \mathrm{rpm}, 175 \mathrm{rpm}$ and, $225 \mathrm{rpm}$. The numerical analysis was made based on the Computational Fluid Dynamic Method (CFD) to calculate the pressure ratio $(\Delta P)$ and percentages of the cavitation area $\left(R_{s}\right)$ due to a configuration of the propellers parameter. The simulation consists of the 3 steps; pre-processor, solver manager, and post-processor. The result shows that the value of the pressure ratio increased significantly at the higher $P / D_{b}$ and $n P r o p$. Also, the variation of $P / D_{b}$ and $n P r o p$ has a significant effect on the

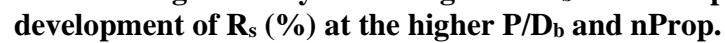

Keywords—cavitation, computational fluid dynamic, CPP, kaplan-series propeller, nProp, pitch ratio.

\section{INTRODUCTION}

Cavi avitation in the majority of cases is known as the formation of the vapor phase of a liquid when it is subjected to decreased pressures $(p)$ at constant ambient temperature, or as the process of rupturing a liquid indicated by a pressure decrease at a roughly constant liquid temperature [1]. The formation of cavities (vapor bubbles) in the fluid flow caused by a pressure drop below the saturated vapor pressure is known as this phenomenon $(p v)$ [2] see figure 1 .

Cavitation also can be described as a process of breaking fluid in the medium under excessive tensile stress based on the continuum mechanics view angle [3]. There is a big difference in the driving mechanism between boiling and cavitation as shown in Figure.1. Boiling is described as a formation of bubbles in the liquid as an influence of the fluid temperature to specific values at constant pressure, whereas cavitation is described as a resultant of the fluid pressure that decreases under the saturated vapor pressure at an approximately.

The cavitation occurrence situations typically occur in the fluid as follows: (a) The wall geometry at the fluid flow zone imposes high velocities and a resulting pressure drop due to the influence of a gradual decrease in flow area; (b) In the case of jets and wakes, the shearing between two adjacent flows with a velocities difference involves significant turbulent pressure

Mohammad Danil Arifin, Department of Marine Engineering, Darma Persada University, Jakarta, 13450, Indonesia.

E-mail: danilarifin.mohammad@gmail.com

Frengki Mohamad Felayati, Department of Marine Engineering, Institut Teknologi Sepuluh Nopember, Surabaya, 60111, Indonesia.

E-mail: frengki11@mhs.ne.its.ac.id fluctuations [3]; (c) The character of high unsteadiness of certain flows caused the pressure drop in the fluid flow; (d) The formation of wakes and subsequently attached cavities influenced by the roughness at the fluid flow wall boundary; (e) Owing to the incorrect joining of two or more parts in the mechanical system, there is a high risk of cavitation forming in the interstices; (f) A pressure drop which is produced by the acquired acceleration at the sharp edges immersed in the liquid, inducing the high chances of cavitation occurrence.

Cavitation mostly occurs in nearly all ship propellers, and it might be lead to a serious problem especially for the ship propelling performance [4]. The cavitation that occurred on the propeller blades may have some impact or lead to some severe effects i.e. disturbance noises, vibration on the propulsion system or in the ship hull, and damaged the material of the propeller blades and rudder [5][6][7]. As a result, cavitation becomes an important factor to consider in any ship propulsion design, including its interaction with the environment (see Figure 2).

The main propulsion on various types of ships generally uses a propeller. The type of propeller used varies based on the needs and types of ships operated while sailing. Like tugboats, these ships usually use a type of Kaplan-Series propeller accompanied by a ducted nozzle to increase power. Various modifications have been made to increase the propeller's performance (thrust, torque, and efficiency). Also, the examination results of the cavitation and vibration tests are needed [9].

Parts that are often engineered on a propeller are the propeller blade, hub, and add components. The propeller's geometry applies Bernoulli's law. There are differences in the face area and the back area to provide lift. A difference also can be seen between the trailing and leading edges. The shape of the root in direct contact with the hub is also different from the propeller's tip. The use of variable pitch propellers is currently more 
generally used because of its main advantage in increasing efficiency [10].

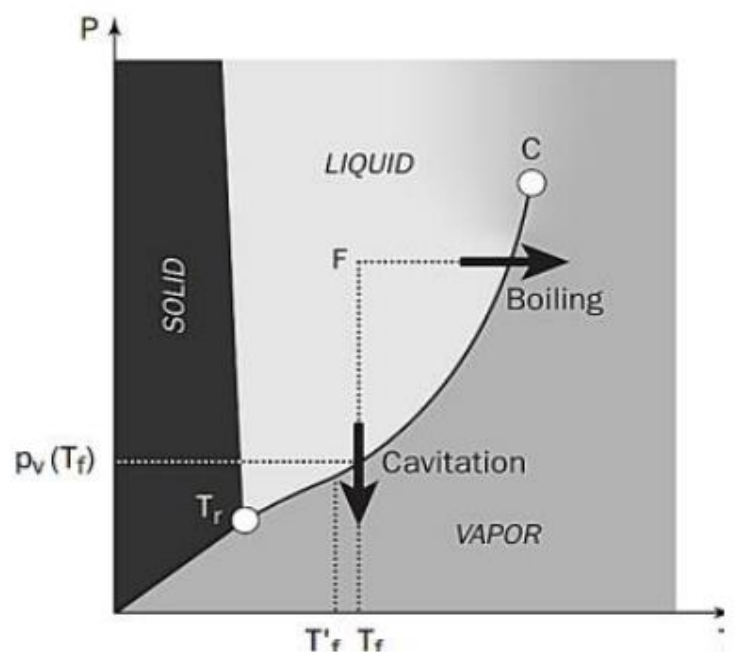

Figure. 1. Thermodynamic diagram of phase change.

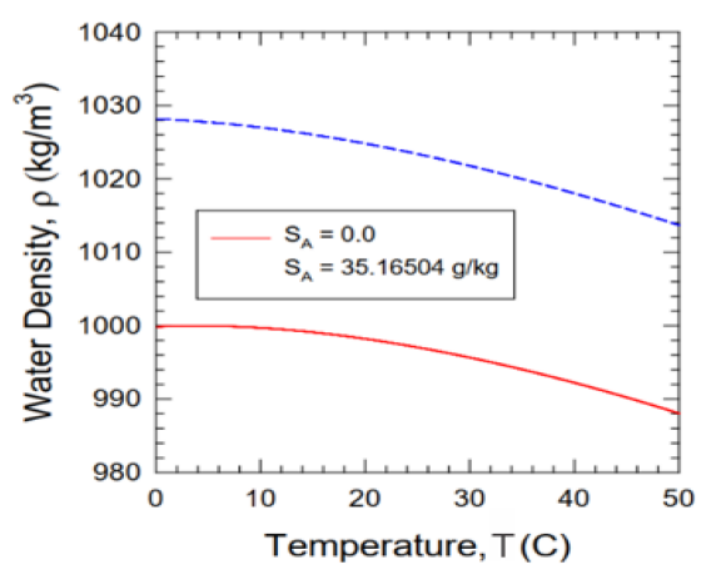

(a)

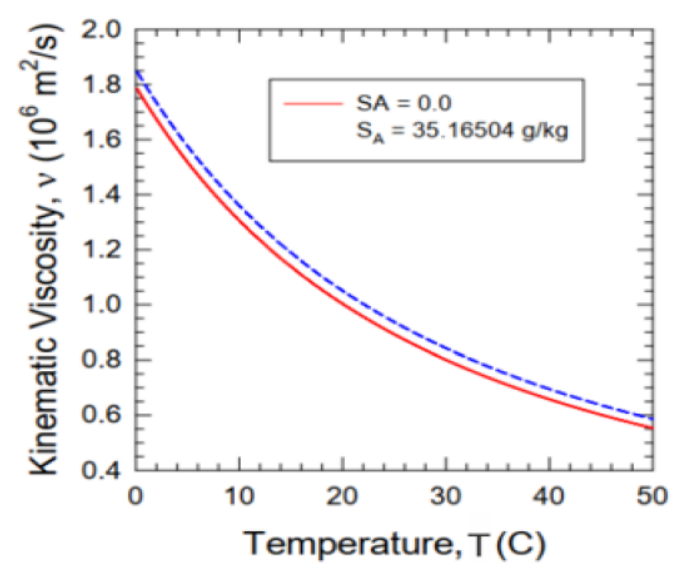

(c)

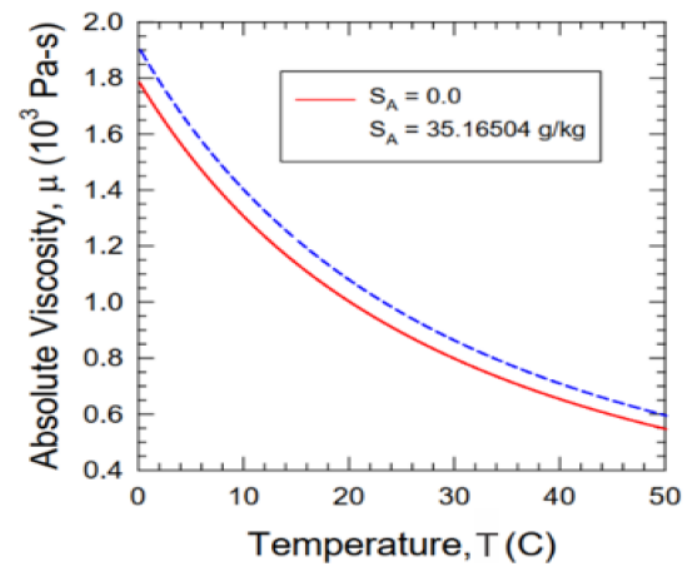

(b)

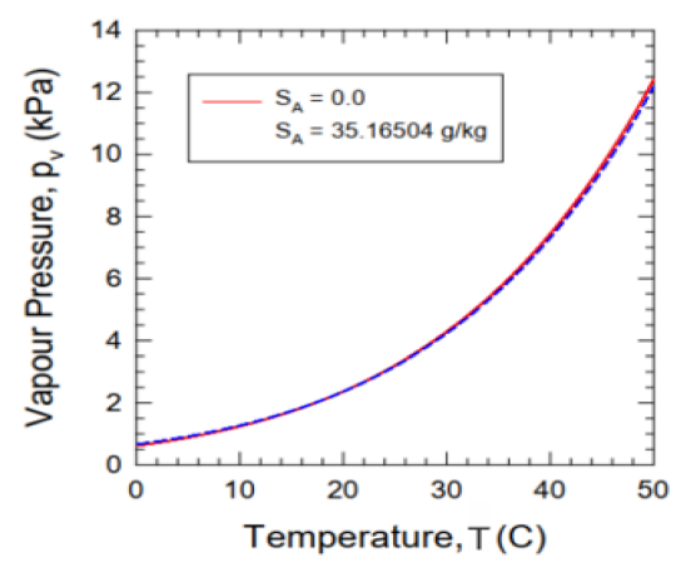

(d)

Figure. 2. (a) Density, (b) dynamic viscosity, (c) kinematic viscosity, and (d) vapor pressure of freshwater and seawater [8].

During recent decades, CFD (Computational Fluid Dynamics) methods had some great advancement for solving the Reynolds Averages Navier Stokes (RANS) equation which applied to various types of marine propeller geometries [11]. Several types of propeller blades have been tested to determine the performance caused by the cavitation on the propeller blades.
Recently, energy-saving devices were developed to improve the performance of propulsion system and fuel consumption of ships, including the reaction of fins for low and high-speed slender ships by developing CFD to examine the type of cavitation occurrence characteristics of the propeller which equipped with the energy-saving devices as a unit [12]. 
Arifin et al, have researched the cavitation on the propeller based on the Computational Fluid-Dynamic (CFD) simulation in order to get the best configuration for the effectiveness of the propeller geometry [13]. Yusvika et al have been analyzed a cavitation prediction on ship propellers based on the temperature and fluid properties of water. It was conducted by doing the cavitation prediction in open water and uniform inflow by the CFD approach, where the simulation was generated by using ANSYS.

In this paper, the numerical prediction of Kaplan Series propeller cavitation is defined based on the computational fluid dynamics (CFD). The aim of this research is to analyze the cavitation of propellers due to a change of variations of $\mathrm{P} / \mathrm{D}_{\mathrm{b}}=0.4, \quad \mathrm{P} / \mathrm{D}_{\mathrm{b}}=0.6$, and $\mathrm{P} / \mathrm{D}_{\mathrm{b}}=0.8$, and variation of $\mathrm{nProp}=125 \mathrm{rpm}$, nProp $=175$ $\mathrm{rpm}$, and nProp=225 rpm. As a result, the calculation of the pressure ratio and the cavitation area for each configuration were examined.

\section{METHOD}

This study used a Kaplan-Series of the CPP propeller type to be simulated. Kaplan propeller is described as a propeller that using axial flow reaction. This type of Kaplan-Series is generally used for a propeller on vessels which usually has 3-7 blades. In this research, the numerical studies of the cavitation analysis are conducted based on the CFD simulation method in several variations of pitch ratio i.e. $\mathrm{P} / \mathrm{D}_{\mathrm{b}}=0.4, \mathrm{P} / \mathrm{D}_{\mathrm{b}}=0.6$, and $\mathrm{P} / \mathrm{D}_{\mathrm{b}}=0.8$, and variation of $\mathrm{nProp}=125 \mathrm{rpm}$, $\mathrm{nProp}=175 \mathrm{rpm}$, and nProp=225 rpm.

TABLE 1.

PRINCIPAL DIMENSION OF THE PROPELLER

\begin{tabular}{clc}
\hline No & Propeller Parameter & Dimension \\
\hline 1 & Type of Propeller & Ka-4 \\
2 & Diameter of Propeller & $0,3 \mathrm{~m}$ \\
3 & Number of Blades & 4 \\
4 & Blades Section & Kaplan-Series \\
5 & nProp (Propeller Rotational Speed) Variations & $125,175,225 \mathrm{rpm}$ \\
6 & P/D (Pitch Ratio Variations) & $0.4,0.6,0.8$ \\
\hline & & $\theta=\tan ^{-1} \frac{P / D_{0.7}}{2 \pi R_{0.7} / D}$ \\
of attack of the Kaplan-Series of the & $\theta=\tan ^{-1} \frac{P / D_{0.7}}{0.7 \pi}$
\end{tabular}
controllable pitch propeller (CPP) is calculated based on the following equation:

Based on the equation (1) and (2) the angle of attack of $\mathrm{P} / \mathrm{D}_{\mathrm{b}}=0.4, \mathrm{P} / \mathrm{D}_{\mathrm{b}}=0.6$, and $\mathrm{P} / \mathrm{D}_{\mathrm{b}}=0.8$ as follows:

TABLE 2.

\begin{tabular}{|c|c|c|c|}
\hline $\mathbf{P} / \mathbf{D}_{0.7}$ & $\left(\mathbf{P} / \mathbf{D}_{0.7}\right) /(0.7 R)$ & $\theta($ rad $)$ & $\theta$ (degree) \\
\hline 0.4 & 0.18189 & 0.1799 & 10.3 \\
\hline 0.6 & 0.27284 & 0.2664 & 15.3 \\
\hline 0.8 & 0.36378 & 0.3486 & 20.0 \\
\hline
\end{tabular}

\section{A. Cavitation Mechanism}

In marine hydrodynamic cavitation is generally caused by fluid flow. That flowing is two-phase flowing consisting of liquid and its liquid steam. Phase transition is created due to changes in hydrodynamic pressure. Depending on the cavitation number, a particular cavitation flow was denoted as $\sigma_{\mathrm{n}}$. The cavitation number $\sigma_{\mathrm{n}}$ and pressure coefficient $c_{\mathrm{p}}$ can be defined as following equations [14]:

$$
\begin{gathered}
\sigma_{n}=\frac{P_{\text {Ref }}-P_{v}}{\frac{1}{2} \rho(n D)^{2}} \\
c_{p}=\frac{P-P_{\text {Ref }}}{\frac{1}{2} \rho(n D)^{2}}
\end{gathered}
$$

Where the pressure used for a reference is denoted as $P_{R e f}$, and the absolute vapor pressure is denoted as $P_{v}$, and the local pressure is denoted as $P$. The cavitation inception is basically classified based on $\sigma_{\mathrm{n}}$ and $\sigma_{\mathrm{p}}$. If $\sigma_{\mathrm{n}}$ $\leq \sigma_{\mathrm{p}}$, cavitation will occur.

\section{B. Propeller Modeling}

The propeller model is constructed based on the principal dimensions of the propeller. In this study, propeller modeling was conducted by using the propeller modeling software PropCad. The result of the propeller model using propeller coordinate processing software is shown in Figure. 3. The configuration of the propeller model is shown as follows: 


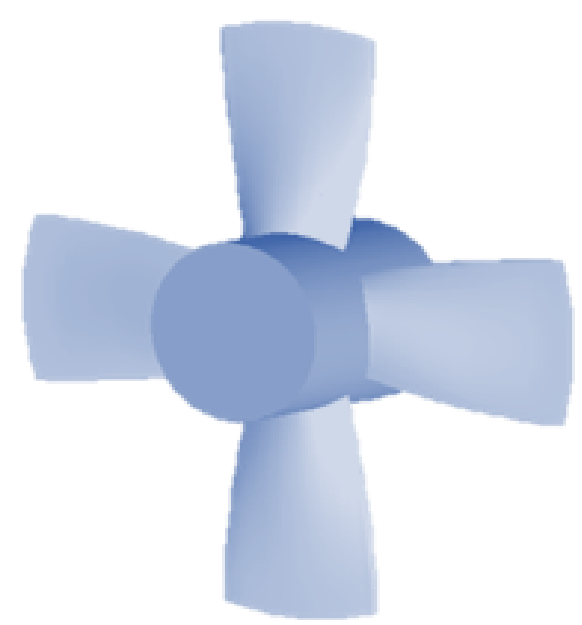

Figure. 3. Propeller modeling by using PropCad.

TABLE 3.

PROPELLER DESIGN SPECIFICATION AND VARIATIONS

\begin{tabular}{ccccc}
\hline Type & $\mathrm{D}_{\mathrm{b}}(\mathrm{cm})$ & $\mathrm{P} / \mathrm{D}_{\mathrm{b}}$ & $\theta($ degree $)$ & $\mathrm{n}(\mathrm{rpm})$ \\
\hline Kaplan-Series & 30 & 0.4 & 10.3 & 125 \\
Ka-4 & 30 & 0.4 & 10.3 & 10.3 \\
& 30 & 0.4 & 15.3 & 225 \\
\hline Kaplan-Series & 30 & 0.6 & 15.3 & 125 \\
Ka-4 & 30 & 0.6 & 15.3 & 175 \\
& 30 & 0.6 & 20.0 & 225 \\
Kaplan-Series & 30 & 0.8 & 20.0 & 125 \\
Ka-4 & 30 & 0.8 & 20.0 & 175 \\
\end{tabular}

The next step of the propeller modeling process is to make a 3D model using ANSYS by checking the geometry and make sure that the model is perfectly formed into a solid object before entering the simulation stage based on the CFD approach.

\section{Computational Fluid Dynamic (CFD)}

Computational Fluid Dynamics is the emerging fields of fluid mechanics in which simulates fluid flows and analyze the characteristic of flow uses numerical and algorithms methods to solve problem-related to fluid flow.

The aim of the CFD methods is to make a prediction accurately i.e. the heat transfer, the flow of fluid, and chemical reaction in the complex systems, including all of the above phenomena. Such a kind of technique is very useful and can be applied in every industrial and non-industrial field.

There are several benefits of the CFD application based on the experimental approach to fluid dynamic system design as follows: (a) For an experimental test with high accuracy, it can minimize the cost and time for designing a product; (b) It has an ability as a study system that can control experiments which is impossible to be conducted by experimental, etc.

In this study, the existing problem is described into CFD software by describing the model and determine the boundary conditions. Moreover, in the solver manager, the problem is calculated by the Navier Stroke equation approach. Then, based on the calculation result to obtain the output of the running program CFD. These three elements can be described as follows:

\section{1) Pre-Processor}

The pre-processor includes input from the flow problem to a CFD program and transforms the input to a form that suitable for use by the solver. The simulations were run in $3 \mathrm{D}$ with the assumption of a steady state. There are two parts to describe in this case: an object and a fluid boundary that is divided into two pieces: a moving component and a fixed part.

The computational domain for the simulation was a cylinder, as seen in Figures 4 and 5. The boundary on the $\mathrm{x}$-axis $\mathrm{z}$ plane is established at this point, and the boundary sections such as inlet, outlet, and wall set are defined. 


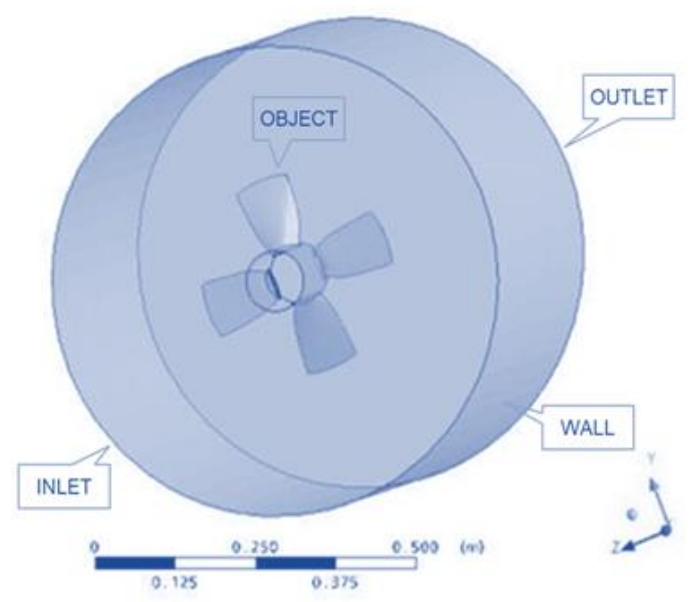

Figure. 4. Geometry stage of propeller simulation.

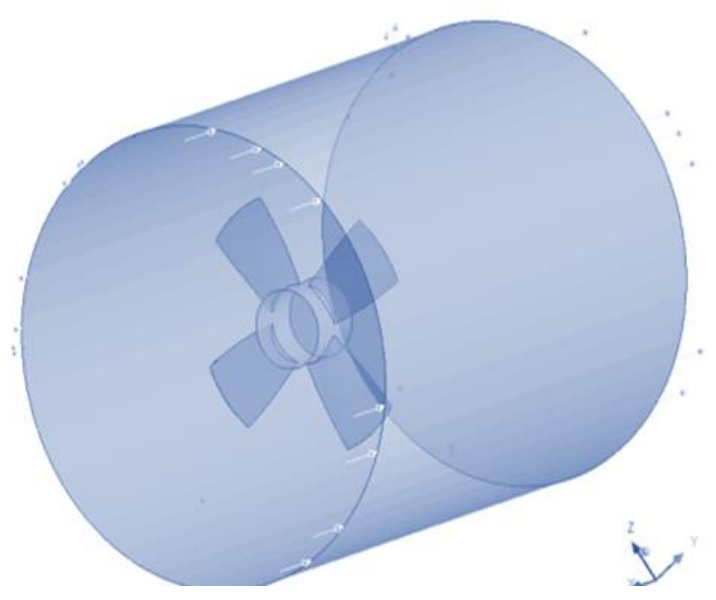

Figure. 5. Boundary layer and subdomain.

2) Solver-Manager

There are three types of methods in the solvermanager: finite element, finite difference, and spectral form. The next move is to perform a meshing operation. As shown in Figure 6, the mesh was generated using the CFX solver mesh. Meshing with an unstructured grid and a hybrid mesh is the preferred method for simulation because it provides high precision. The numerical mesh is created in order to capture the flow field's related behaviors. The cavitation simulation on the Ka-4 propeller blades in this analysis was done under steadystate conditions.

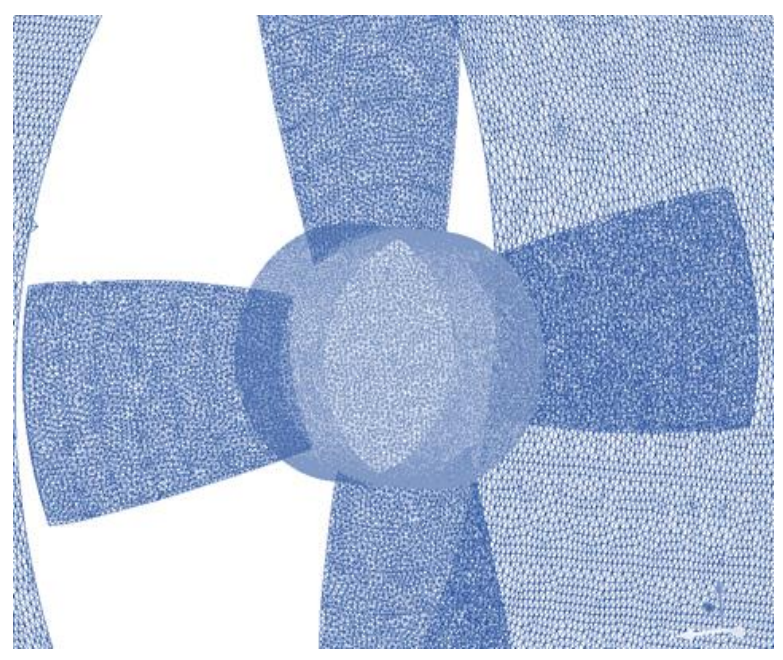

Figure. 6. Mesh of the rotary and fixed domain. 
3) Post-Processor

After a simulation, we can examine and analyze the results of the model simulation through CFD-Post. Postprocessor is defined as a stage of visualization of the previous stage (Pre-processor and Solver Manager) which growing with the advancement of engineering workstations that are equipped with great graphics and visualization capabilities.

\section{RESULTS AND DISCUSSION}

\section{A. Pressure Analysis of the Ka-4 Propeller}
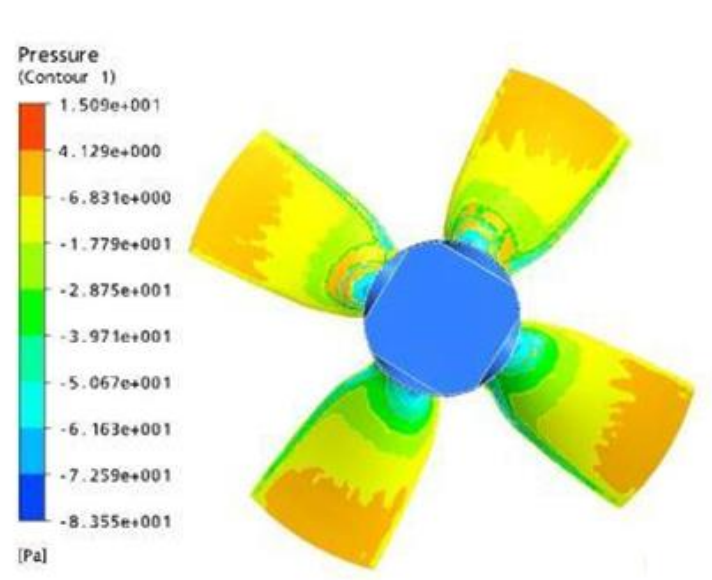

[Pa]

(a) $\mathrm{P} / \mathrm{D}_{\mathrm{b}}=\mathbf{0 . 4}$
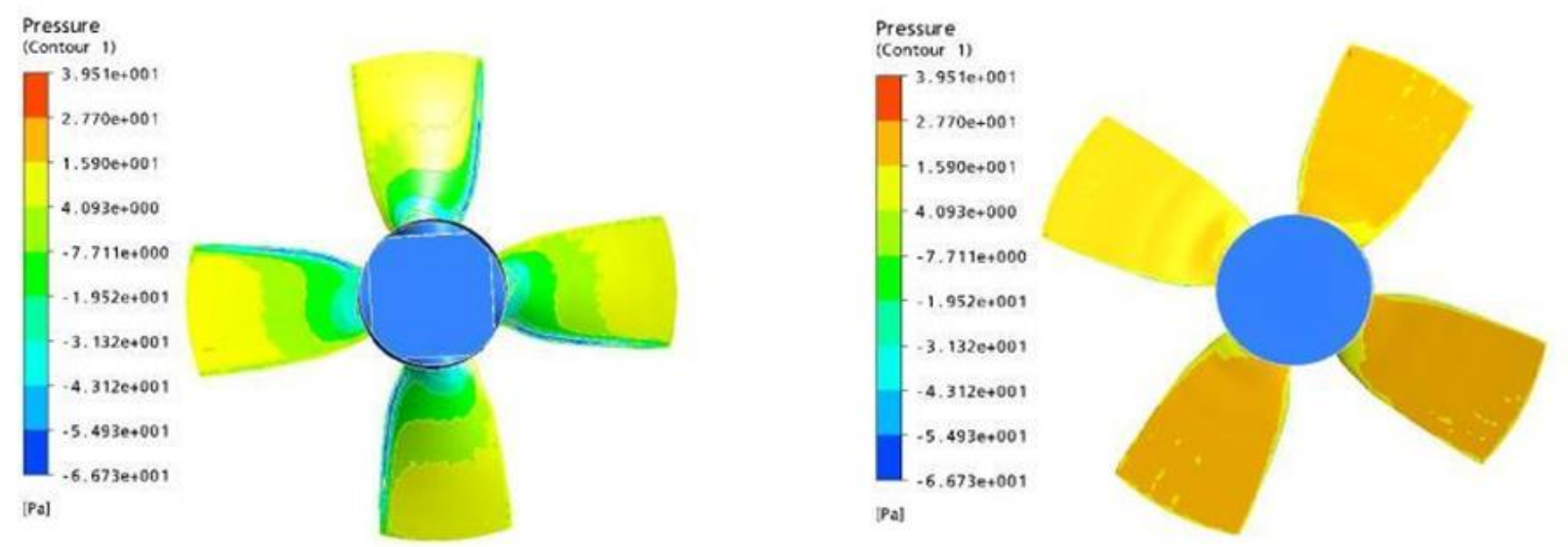

(b) $\mathbf{P} / \mathbf{D}_{\mathrm{b}}=0.6$
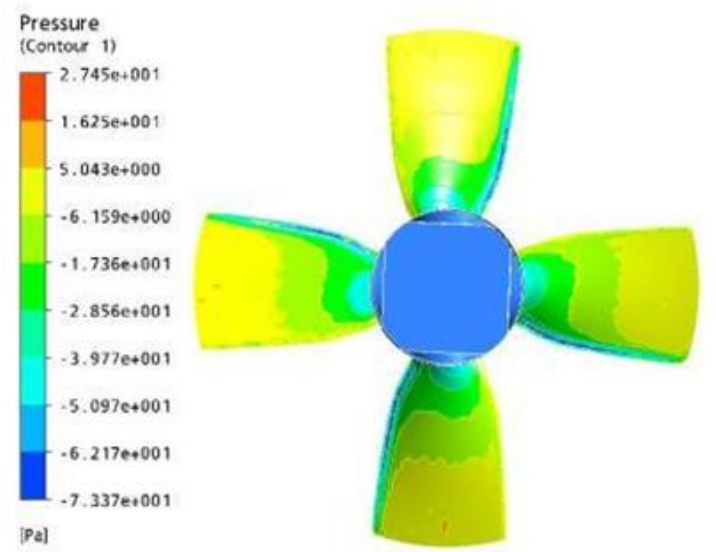

The influence of the flow in which past the blades is caused by positive pressure on the face part and reduced pressure or suction on the back part due to increased velocities of flow. The increased velocity itself is influenced by the shape of the propeller blades. In order to examine the $\Delta P$ between the $P$ on the face and back sides of the blades, the CFD simulation was conducted by varying the $\mathrm{P} / \mathrm{D}_{\mathrm{b}}$ and $\mathrm{nProp}$. The result of $\Delta P$ of face and back sides is shown in Table 4. However, simulation results as a pressure contour are shown in Figure 7 as follows:

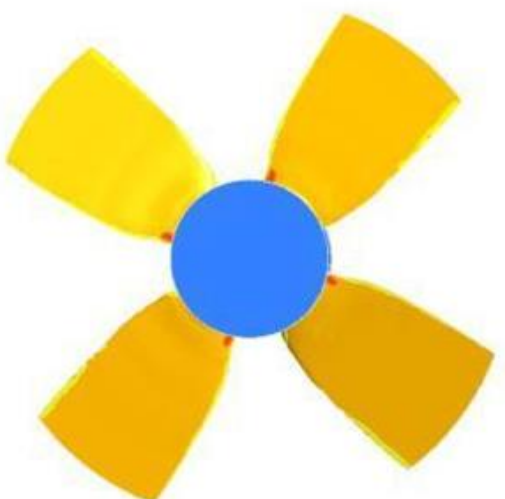

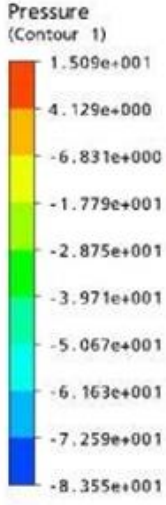

Pel .

\section{.} . 
TABLE 4.

PROPELLER DESIGN SPECIFICATION AND VARIATIONS

\begin{tabular}{|c|c|c|c|c|c|}
\hline \multirow{2}{*}{ Diameter (m) } & \multirow{2}{*}{$\mathrm{P} / \mathrm{D}_{\mathrm{b}}$} & nProp & P Face & P Back & $\Delta \mathrm{P}$ \\
\hline & & (rpm) & $\left(\mathrm{N} / \mathrm{m}^{2}\right)$ & $\left(\mathrm{N} / \mathrm{m}^{2}\right)$ & $\left(\mathrm{N} / \mathrm{m}^{2}\right)$ \\
\hline \multirow{3}{*}{0.3} & 0.4 & 125 & 312839 & 300855 & 11984 \\
\hline & 0.6 & 125 & 348508 & 334572 & 13936 \\
\hline & 0.8 & 125 & 316844 & 297462 & 19382 \\
\hline \multirow{3}{*}{0.3} & 0.4 & 175 & 528349 & 512349 & 16000 \\
\hline & 0.6 & 175 & 639036 & 614639 & 24397 \\
\hline & 0.8 & 175 & 581393 & 550106 & 31287 \\
\hline \multirow{3}{*}{0.3} & 0.4 & 225 & 959863 & 937404 & 22459 \\
\hline & 0.6 & 225 & 998361 & 961033 & 37328 \\
\hline & 0.8 & 225 & 904723 & 852328 & 52395 \\
\hline
\end{tabular}

It can be seen that there is a difference between the $P$ at the face and back sides of the propeller in all conditions due to a variation on $\mathrm{P} / \mathrm{D}_{\mathrm{b}}$ and $\mathrm{nProp}$. The correlation between the parameter of $\mathrm{P} / \mathrm{D}_{\mathrm{b}}$ and nProp to simulation results of pressure, the ratio is shown in Figures 8 to 9.

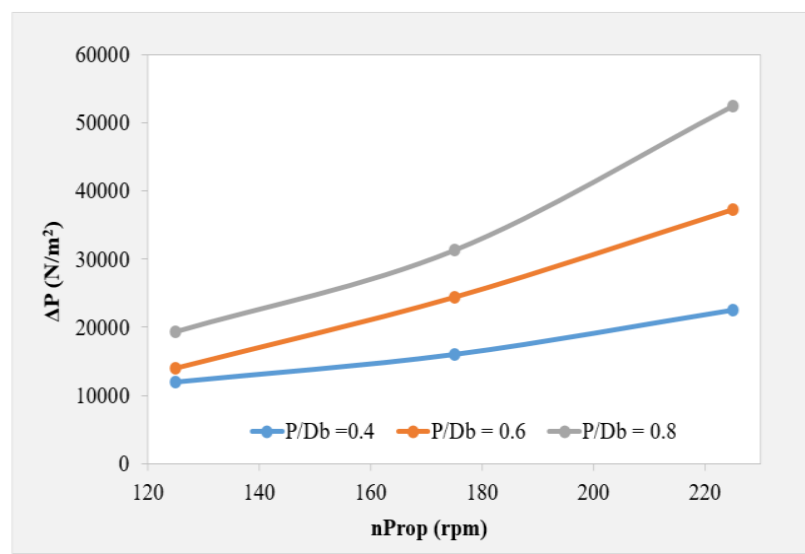

Figure. 8. The pressure ratio of Ka-4 with a variation of nProp.

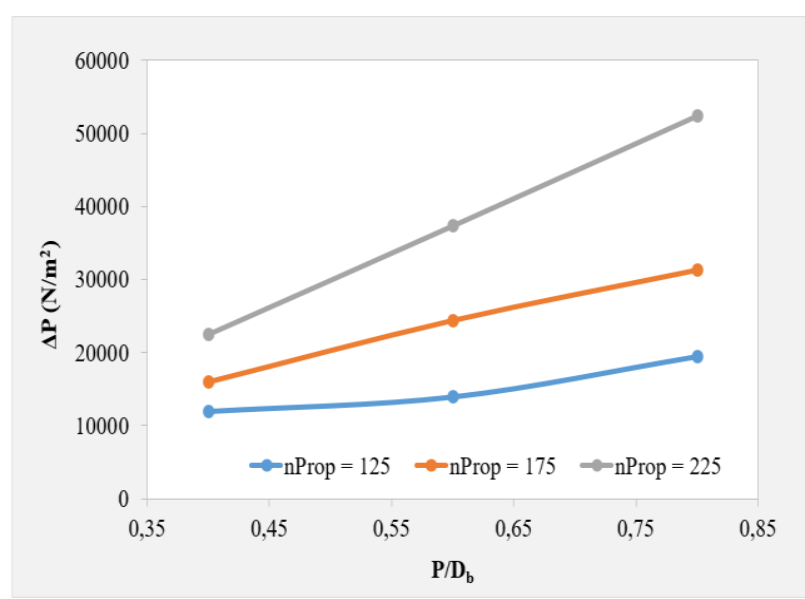

Figure. 9. The pressure ratio of Ka- 4 with a variation of $\mathrm{P} / \mathrm{D}_{\mathrm{b}}$.

As shown by the pressure contours results in Figure 7 , as the pitch ratio increases from 0.4 to 0.8 , there is an increase in pressure on the blade surfaces. It is slightly seen in the distribution on the blades. The increase in pressure on the pressure side; face and back sides creates an increase in the generated pressure ratio as well. It is confirmed by the results shows in Table 4 and Figures 8 to 9 . It is found that the pressure ratio of the face and back propeller of $\mathrm{Ka}-4$ gradually increases follows by the change of both nProp (rpm) and P/D .

When the propeller model was simulated at nProp $=$ $125 \mathrm{rpm}$, the pressure ratio increases from $11984 \mathrm{~N} / \mathrm{m}^{2}$ to 13936, and reach to the maximum value i.e. $19382 \mathrm{~N} / \mathrm{m}^{2}$ follows by the change of $\mathrm{P} / \mathrm{D}_{\mathrm{b}}=0.4, \mathrm{P} / \mathrm{D}_{\mathrm{b}}=0.6$, and $\mathrm{P} / \mathrm{D}_{\mathrm{b}}=0.8$. When the $\mathrm{nProp}=175 \mathrm{rpm}$, the pressure ratio also increases from $16000 \mathrm{~N} / \mathrm{m}^{2}$, to $24397 \mathrm{~N} / \mathrm{m}^{2}$, and reaching into $31287 \mathrm{~N} / \mathrm{m}^{2}$.

The higher value of pressure ratio is shown by the 
model simulation results while the propeller was operated on nProp $=225 \mathrm{rpm}$ where the pressure ratio increases from $22459 \mathrm{~N} / \mathrm{m}^{2}$, to $37328 \mathrm{~N} / \mathrm{m}^{2}$, and ends up with $52395 \mathrm{~N} / \mathrm{m}^{2}$. These results indicate that there is a significant relationship between the increases of $P / D_{b}$ and nProp to an increase of pressure ratio produced during the simulation process.

\section{B. Cavitation}

In order to examine the influence of the pitch ratio and the propeller rotational speed on the cavitation area on the blade surface, the CFD model simulation was conducted. Three pitch ratio were used i.e. $\mathrm{P} / \mathrm{D}_{\mathrm{b}}=0.4$, $\mathrm{P} / \mathrm{D}_{\mathrm{b}}=0.6$, and $\mathrm{P} / \mathrm{D}_{\mathrm{b}}=0.8$; and three of propeller rotational speed were set in several speed i.e. nProp $=125 \mathrm{rpm}$, $\mathrm{nProp}=175 \mathrm{rpm}$, and nProp=225 rpm.

Based on the computational fluid dynamic model simulation result, it can be found the characteristic propensity of each cavitation occurrence of each pitch ratio and propeller rotational speed variations. The cavitation that is occurred in each $\mathrm{Ka}-4$ propeller model simulation can be identified by using the isosurface which is available at ANSYS CFX-Post. The area of the isosurface is defined as $S_{\text {iso }}$ the area of the blade is defined as $S_{i}$, and the area ratio is defined as $R_{\mathrm{s}}=S_{\text {iso }} / S_{i}$ [15]. The cavitation is identified by measuring or calculating the area ratio $R_{s}$. The model simulation results as the pitch ratio $\left(\mathrm{P} / \mathrm{D}_{\mathrm{b}}\right)$ and propeller rotational speed (nProp) increase is represented by Figure 10.

Figure 10 (a) shows the propeller cavitation model simulation of $\mathrm{Ka}-4$ propeller with variation of pitch ratio $\mathrm{P} / \mathrm{D}_{\mathrm{b}}=0.4, \mathrm{P} / \mathrm{D}_{\mathrm{b}}=0.6$, and $\mathrm{P} / \mathrm{D}_{\mathrm{b}}=0.8$, with $\mathrm{nProp}=125$ $\mathrm{rpm}$. Figure 10 (b) shows the propeller cavitation model simulation of $\mathrm{Ka}-4$ propeller with variation of pitch ratio $\mathrm{P} / \mathrm{D}_{\mathrm{b}}=0.4, \mathrm{P} / \mathrm{D}_{\mathrm{b}}=0.6$, and $\mathrm{P} / \mathrm{D}_{\mathrm{b}}=0.8$, with $\mathrm{nProp}=175$ rpm. However, Figure 10 (c) shows the propeller cavitation model simulation of Ka-4 propeller with variation of pitch ratio $\mathrm{P} / \mathrm{D}_{\mathrm{b}}=0.4, \quad \mathrm{P} / \mathrm{D}_{\mathrm{b}}=0.6$, and $\mathrm{P} / \mathrm{D}_{\mathrm{b}}=0.8$, with $\mathrm{nProp}=225 \mathrm{rpm}$.

The calculation results of the cavitation area for each configuration model propeller are represented by the percentages $(\%)$ area of the produced cavitation that occurred during the simulation. The result is shown in Table 5 on the next pages.

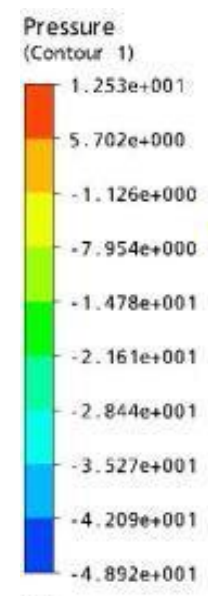

[Pa]

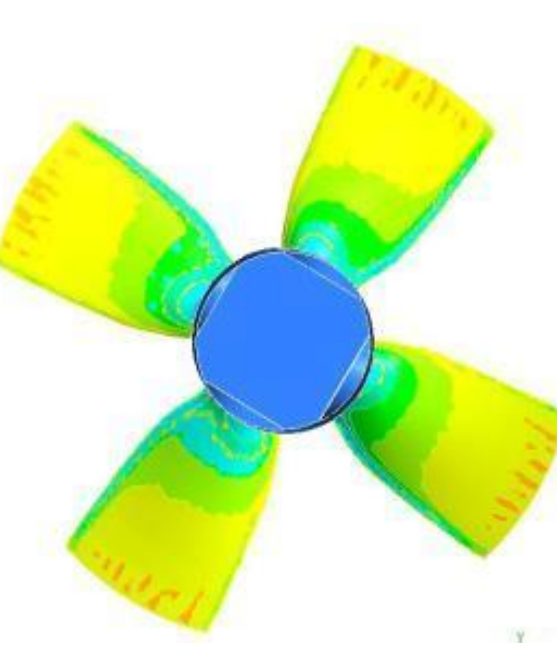

(a) $\mathrm{nProp}=125 \mathrm{rpm}$

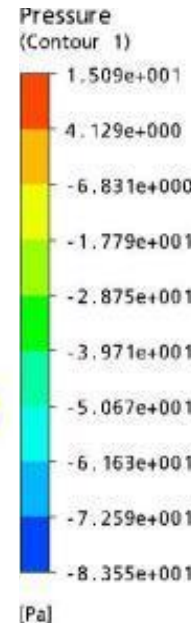

[Pa]

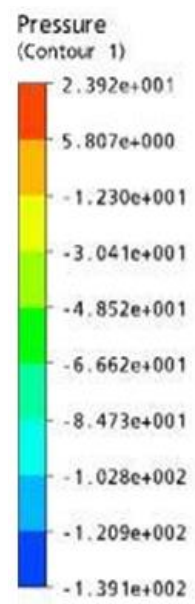

[Pa]

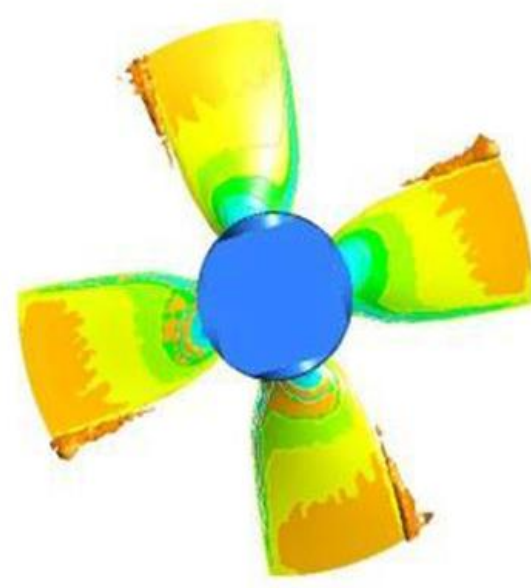

(c) nProp $=225 \mathrm{rpm}$

Figure. 10. Cavitation area of Ka-4 Series Propeller with $\mathrm{P} / \mathrm{D}_{\mathrm{b}}=0.4$. 


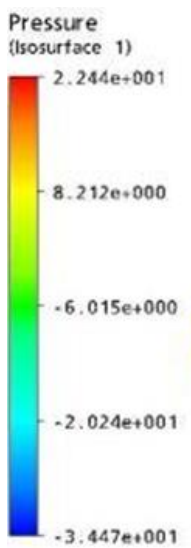

[Pa]

(a) nProp $=125 \mathrm{rpm}$

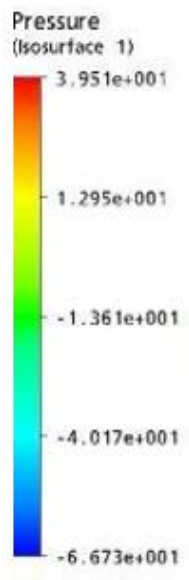

[Pa]

(b) $\mathrm{nProp}=175 \mathrm{rpm}$

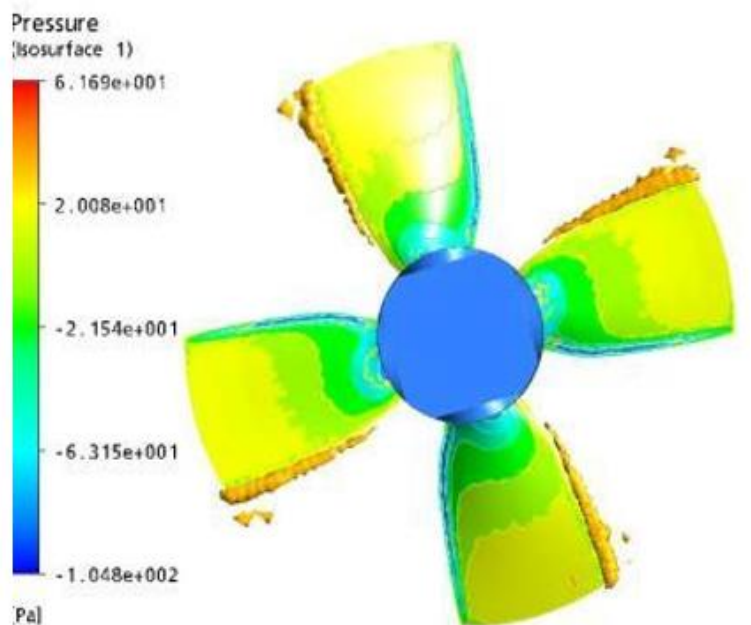

(c) nProp $=225 \mathrm{rpm}$

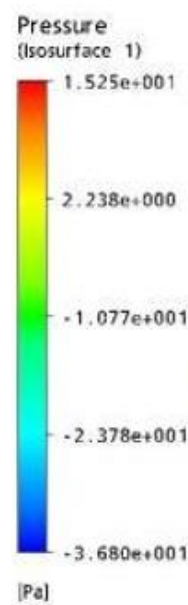

(a) nProp $=125 \mathrm{rpm}$

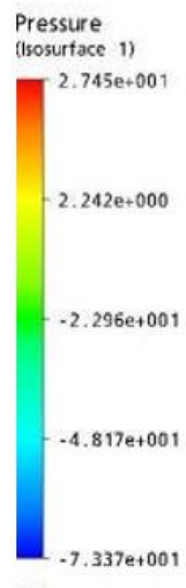

[Pa]

(b) nProp $=175 \mathrm{rpm}$

Pressure

(lsosurface 1)

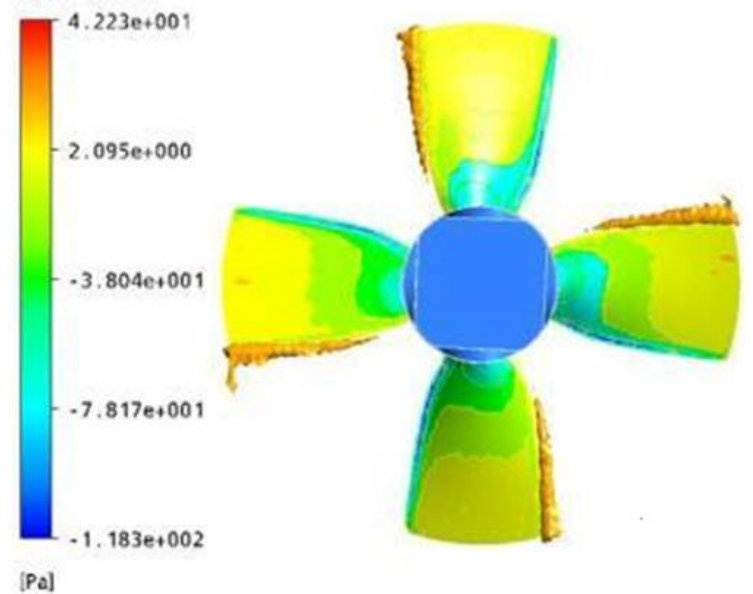

(c) $\mathrm{nProp}=225 \mathrm{rpm}$
Figure. 11. Cavitation area of Ka-4 Series Propeller with $\mathrm{P} / \mathrm{D}_{\mathrm{b}}=0.6$.
Figure. 12. Cavitation area of Ka-4 Series Propeller with $\mathrm{P} / \mathrm{D}_{\mathrm{b}}=0.8$. 
TABLE 5.

PERCENTAGE OF THE CAVITATION AREA-RS (\%)

\begin{tabular}{cccccc}
\hline & $\mathrm{nProp}$ & $\Delta \mathrm{P}$ & $\mathrm{S}_{\mathrm{i}}$ & $\mathrm{S}_{\text {iso }}$ & $\mathrm{R}_{\mathrm{s}}$ \\
\cline { 2 - 6 } & $(\mathrm{rpm})$ & $\left(\mathrm{N} / \mathrm{m}^{2}\right)$ & $\left(\mathrm{m}^{2}\right)$ & $\left(\mathrm{m}^{2}\right)$ & 0 \\
\hline 0.4 & 125 & 11984 & 0.0329831 & 0 & 0 \\
0.6 & 125 & 13936 & 0.0329831 & 0 & 0 \\
0.8 & 125 & 19382 & 0.0329831 & 0 & 1.44 \\
0.4 & 175 & 16000 & 0.0329831 & 0.000476 & 1.92 \\
0.6 & 175 & 24397 & 0.0329831 & 0.000632 & 1.41 \\
\hline 0.8 & 175 & 31287 & 0.0329831 & 0.000464 & 0.000111 \\
0.4 & 225 & 22459 & 0.0329831 & 0.001271 & 3.38 \\
0.8 & 225 & 37328 & 0.0329831 & 0.001391 & 3.85 \\
\hline
\end{tabular}

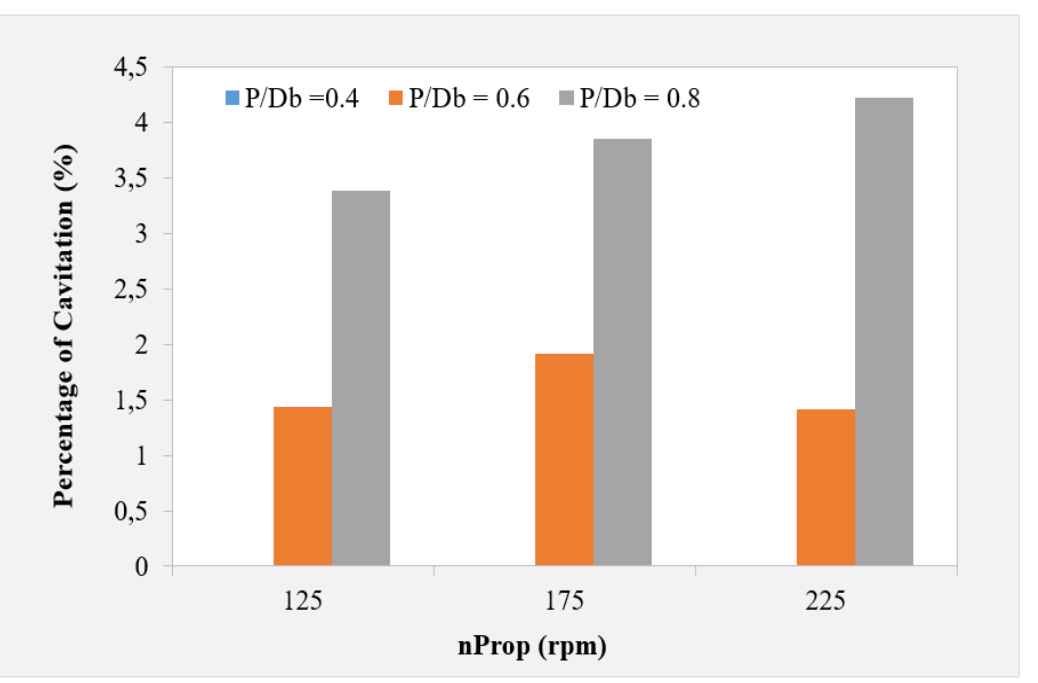

Figure. 13. Percentage of $R_{s}$ with a variation of nProp.

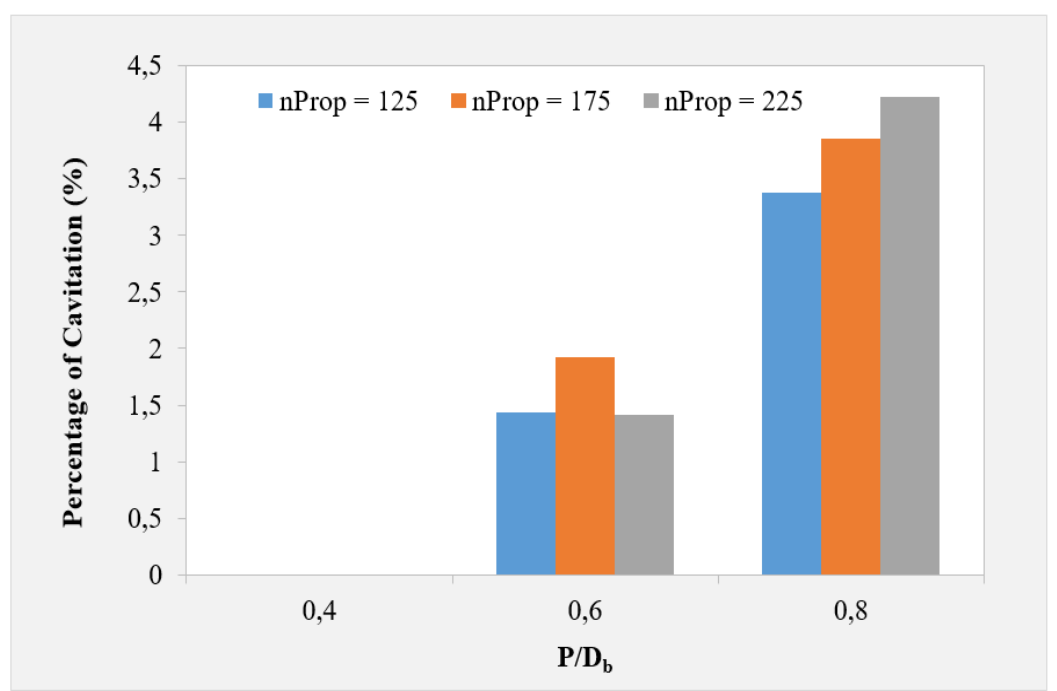

Figure. 14. Percentage of $R_{s}$ with a variation of $P / D_{b}$.

As mentioned in the previous section, the percentages of cavitation area are shown in Table 5. The relationship between $\mathrm{P} / \mathrm{Db}$ - nProp with cavitation area denoted by Rs is represented by Figure 13-14. Based on the simulation results, it can be found that the cavitation area $R_{s}$ is influenced by the nProp and $P / D_{b}$. The $R_{s}$ tend to increase on a higher the nProp and $\mathrm{P} / \mathrm{D}_{\mathrm{b}}$. In the case of $\mathrm{P} / \mathrm{D}_{\mathrm{b}}=0.4$, the $\mathrm{R}_{\mathrm{s}}$ in an increase from 0 , to $1.44 \%$, and reach into $3.38 \%$ follows by the increases of nProp from $125 \mathrm{rpm}$, to $175 \mathrm{rpm}$, and the highest is $225 \mathrm{rpm}$. Moreover, in the case $\mathrm{P} / \mathrm{D}_{\mathrm{b}}=0.6$, the $\mathrm{R}_{\mathrm{s}}$ in increase from 0 at $125 \mathrm{rpm}$, to $1.92 \%$ at $175 \mathrm{rpm}$, and reach $3.85 \%$ at 
$225 \mathrm{rpm}$. Furthermore, in the case of $\mathrm{P} / \mathrm{D}_{\mathrm{b}}=0.8$, the $\mathrm{R}_{\mathrm{s}}$ in the increase from 0 at $125 \mathrm{rpm}, 1.41 \%$ at $175 \mathrm{rpm}$, and $4.22 \%$ at $225 \mathrm{rpm}$.

\section{CONCLUSION}

This research analyzes the effect of pitch ratio $\left(\mathrm{P} / \mathrm{D}_{\mathrm{b}}\right)$ and rotational speed propeller (nProp) on cavitation on the Ka-4 (Kaplan-Series) propeller. A computational fluid of dynamic approach is used to identify the pressure ratio affected by the configuration of $\mathrm{P} / \mathrm{D}_{\mathrm{b}}$ and nProp. Moreover, it was used to analyze the cavitation area by using isosurface pressure on CFX-Post. There are several conclusions from the model simulation:

a. The $\mathrm{P} / \mathrm{D}_{\mathrm{b}}$ and $\mathrm{nProp}$ significantly impact the pressure ratio between the face and back propeller. The pressure ratio tends to increase follows by the increases of the several variations of $\mathrm{P} / \mathrm{D}_{\mathrm{b}}$ and $\mathrm{nProp}$. The higher value of pressure ratio shows while the propeller model simulated at $225 \mathrm{rpm}$ and $\mathrm{P} / \mathrm{D}_{\mathrm{b}}=0.8$, where the pressure ratio increases from $22459 \mathrm{~N} / \mathrm{m}^{2}$, to $37328 \mathrm{~N} / \mathrm{m}^{2}$, and end up with $52395 \mathrm{~N} / \mathrm{m}^{2}$.

b. The $P / D_{b}$ and nProp significantly impact the percentage of cavitation area, denote by $R_{\mathrm{s}}$. It tends to increase follows by the increases in pressure ratio, $\mathrm{P} / \mathrm{D}_{\mathrm{b}}$, and nProp. Whereas at nProp $=125 \mathrm{rpm}$ and $\mathrm{P} / \mathrm{D}_{\mathrm{b}}=0.4$, the $\mathrm{R}_{\mathrm{s}}$ is zero; and then slightly increase from $1.44 \%$ to $3.38 \%$. The highest $\mathrm{R}_{\mathrm{s}}$ has occurred while the propeller was simulated at $\mathrm{nProp}=225 \mathrm{rpm}$ and $\mathrm{P} / \mathrm{D}_{\mathrm{b}}=0.8$. It is significantly increased from zero to $1.41 \%$ and reaching a higher value of around $4.22 \%$.

\section{REFERENCES}

[1] Phillips Eidenberg., "Cavitation”, Section 12 Handbook of Fluid Mechanics, McGraw-Hill Book Co., Inc (Section 12-I: Mechanics of Cavitation), pp. 121-128. 1961.

[2] Binama Maxime, Emanuel Bisengimana, Alexis Muhirwa., "Cavitation Effects in Centrifugal Pumps-A Review", International Journal of Engineering Research and Applications., Vol. 6. No. 5 (Part 1). pp. 52-63. 2016.

[3] Michel, J.M., introduction to cavitation and supercavitation, (Centre national de la recherché scientifique grenoble (france) lab de ecoulements geophysiques/industriels, 2001)

[4] Tom van Terwisga, Johan Bosschers, Erik Van Wijngaarden, and Gerrit Kuiper. "Achievements and challenges in cavitation research on ship propellers", International Shipbuilding Progress, Vol. 54, Number 2-3, pp. 1-22. 2007

[5] Themistoklis I. Melissaris, Tom van Terwisga, Norbert Bulten, "Cavitation Aggressiveness and Cavitation Erosion on Marine Propellers using a URANS Method," 10th International Symposium on Cavitation - CAV2018., Baltimore, Maryland, USA, May 14 - 16, pp. 832-843. 2018.

[6] M.D. Arifin, D. Faturachman, F. Octaviani, K. A. Sulaeman, "Analysis of the Effect of Changes in Pitch Ratio and Number of Blades on Cavitation on CPP," International Journal of Marine Engineering Innovation and Research., Vol. 5. No. 4, pp. $255-$ 264, 2020.

[7] M.D. Arifin, D. Faturachman, F. Octaviani, “Analisa Pengaruh Perubahan Pitch Ratio dan Jumlah Blade Terhadap Kavitasi
Pada Controllable Pitch Propeller (CPP)," Jurnal Sains dan Teknologi Fakultas Teknik Universitas Darma Persada., Vol. 9. No. 2, pp. 74-85, 2020.

[8] Cooper, J.R.; Dooley, R.B. Revised Release on the IAPWS Industrial Formulation 1997 for the Thermodynamic Properties of Water and Steam; The International Association for the Properties of Water and Steam (IAPWS): Lucerne, Switzerland, 2007.

[9] M. M. Shora, H. Ghassemi, and H. Nowruzi, "Using computational fluid dynamic and artificial neural networks to predict the performance and cavitation volume of a propeller under different geometrical and physical characteristics," J. Mar. Eng. Technol., vol. 17, no. 2, pp. 59-84, 2018.

[10] S. Kapuria and H. N. Das, "Improving hydrodynamic efficiency of composite marine propellers in off-design conditions using shape memory alloy composite actuators," Ocean Eng., vol. 168, pp. 185-203, 2018.

[11] S. Subhas, V F Saji, S. Ramakrishna, and H. N Das "CFD Analysis of a Propeller Flow and Cavitation," International Journal of Computer Applications (0975 - 8887)., Vol. 55. No. 16. pp. 26-33, 2012.

[12] Kawakita, C. et al. "CFD on Cavitation around Marine Propellers with Energy-Saving Devices", Mitsubishi Heavy Industries Technical Review Vol. 49 No. 1 (March 2012)

[13] Arifin, M.D. et al. "Analisa Kavitasi Terhadap Perubahan Kerja Pitch dan Jumlah Blade Pada CPP” Surabaya, 2010.

[14] Helal, M.M.; Ahmed, T.M.; Banawan, A.A.; Kotb, M.A. Numerical Prediction of Sheet Cavitation on Marine Propellers Using CFD Simulation with Transition-Sensitive Turbulence Model. Alexandria Eng. J. 2018, Vol. 57, pp. 3805-3815.

[15] Long Yun.; Zhu Rongsheng.; Wang Dezhong, "A performance prediction method for pumps PARTI-Proposal and feasibility". Journal of Nuclear Engineering and Technology. 2020, Vol. 52, pp. 2471-2478. 